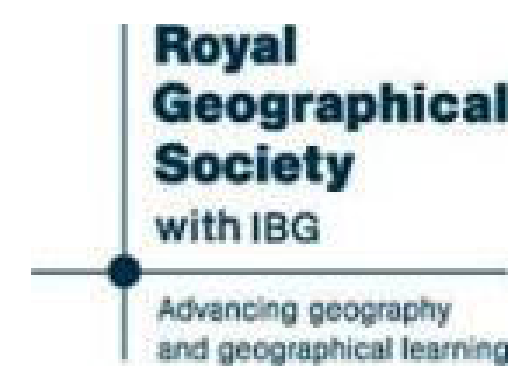

How Are We to Get Maps of Africa?

Author(s): T. H. Holdich

Source: The Geographical Journal, Vol. 18, No. 6 (Dec., 1901), pp. 590-601

Published by: The Royal Geographical Society (with the Institute of British Geographers)

Stable URL: http://www.jstor.org/stable/1775360

Accessed: 09/01/2015 08:42

Your use of the JSTOR archive indicates your acceptance of the Terms \& Conditions of Use, available at

http://www.jstor.org/page/info/about/policies/terms.jsp

JSTOR is a not-for-profit service that helps scholars, researchers, and students discover, use, and build upon a wide range of content in a trusted digital archive. We use information technology and tools to increase productivity and facilitate new forms of scholarship. For more information about JSTOR, please contact support@ jstor.org. 


\title{
HOW ARE WE TO GET MAPS OF AFRICA?*
}

\author{
By Colonel Sir T. H. HOLDICH, K.C.B., C.B., R.E.
}

At the meeting of the British Association which was held at Bradford in the year 1900, a committee of the Geographical Section was formed for the consideration of certain general principles which should be adopted in developing the mapping of the African continent, and which would ensure (inter alia) that full use should be made of all the geographical material which is gradually being amassed, not only under Government direction, but by independent travellers working in the interests of the Royal Geographical Society.

The resolution which that sub-committee presented at the Glasgow meeting of the British Association this year is as follows:-

The Survey of British Protectorates.-Report of the Committee, consisting of Sir T. H. Holdich (Chairman), Colonel G. E. Church, Mr. E. G. Ravenstein, and Mr. H. N. Dickson (Secretary), appointed to draw up a Schemefor th: Survey of British Protectorates.

Your Committee are of opinion that a representation should be submitted to His Majesty's Government in support of an organized scheme for surveying British Protectorates in Africa, and that it would be advantageous to secure the cooperation of the Royal Geographical Society, and of other bodies unconnected with Government who may be specially interested in the matter, in bringing forward their proposals. At present, various surveys have been commenced in different parts of Africa under local administrations, which are unconnected with each other and have apparently no common basis of technical system or scale, from which it will be difficult eventually to compile a satisfactory and homogeneous first map of our African possessions. A large amount of geographical work, carried on more or less under the auspices of the Royal Geographical Society, is gradually accumulating, all of which might be usefully turned to account in a general survey scheme, if uniformity of method and scale were adopted. A comprehensive scheme of geographical survey (apart from special surveys for local requirements), to be carried out jointly with other nationalities in the continent of Africa, will undoubtedly prove a necessity in the near future for purposes of boundary demarcation and administration; but such a scheme must emanate from those responsible advisers of Government who are best acquainted with the opportunities for con bined action and the means for carrying it out.

But, pending the adoption of such a scheme, and with due appreciation of the value of the disjointed efforts which are now being made to secure partial surveys for administrative purposes in various parts of the country, your Committee are of opinion that the following considerations, none of which involve immediate financial outlay, should be especially brought to the notice of His Majesty's Government; inasmuch as immediate attention to them would undoubtedly tend to hasten the attainment of the end primarily in view-viz. the construction of a homogeneous and consistent geographical map of that part of Africa which affects Imperial interests.

(1) The advantage of a common scale should be impressed on local administrations who have already commenced surveys within the protectorates under their

* Map, p. 656. 
administration, and every effort should be made in the first instance to secure a general map on the smallest geographical scale which can be made practically useful for purposes of either administration or strategy. This scale should not be less than one in five hundred thousand.

(2) Inasmuch as all future surveys, on whatsoever scale, must ultimately depend on the accuracy of the initial base measurements if they are to fit together into one homogeneous map, it is most desirable to draw the attention of local administrators to this point; and, wherever local surveys have already been commenced, to test the accuracy of their linear measurements by the adoption of a geodetic base. Such a base need not be measured by the cumbersome processes which have made the measurement of geodetic bases so laborious and expensive in the past. New methods and improved means have lately been introduced which greatly simplify the work, but there is no method which does not require scientific direction. It would, therefore, be advisable that the same instruments, under the same personal supervision, should be used in every case. Unity of scale and of linear measurement is absolutely essential to final compilation in such vast areas as Africa presents, and much good work now in progress may be rendered valueless for general map-making purposes if such unity is not secured $a b$ initio.

(3) It is the earnest desire of the Royal Geographical Society that those travellers and explorers who use their instruments and accept their assistance financially should add to the practical outcome of mapping material in Africa. For this purpose the Society has established training classes in practical geography, and keeps a record of the names of those who are qualified to work as geographical surveyors. But in order to utilize their work to the fullest extent, it is essential that the geographical data determined by such professional surveyors as from time to time are sent to Africa under the direction of the Intelligence Department should become generally available; and it is therefore most desirable that all such material (indispensable for the proper location of field surveys and for check on final positions) as may be collated at the Intelligence Office may be placed at the disposal of the Royal Geographical Society. Attention should very specially be drawn to the great amount of geographical mapping (at present disconnected and wanting in topographical detail) which is annually turned out by irresponsible travellers. The value of this might be largely increased if it were based on exact data.

(4) One of the most important factors in dealing with the vast area of our African possessions in the matter of geographical (or first) surveys is the absolute necessity of resorting to native agency for its topography. Effective topography can never be secured without the assistance of surveyors and draughtsmen specially trained to this particular branch of map-making. European agency (except for purposes of supervision) is out of the question on account of the expense. Indian native agency is equally impossible for more than comparatively restricted are s. The vast mass of African mapping must be secured through the agency of natives of Africa, just as Asia has largely been mapped by Asiatics.

There is apparently no reason why natives of Africa, trained in mission aud other schools, should not be as effective in the field of survey as Africans generally have proved in the field of arms.

It is suggested that in the earlier stages of the formation of such an agency scientific societies might be willing to take the initiative. It is to the interest of the Royal Geographical Society, for instance, to secure the assistance of native topographers for explorers. What is immediately wanted is the initiation of a training school; and it seems probable that, if one or two promising pupils were selected from each protectorate for training, an invaluable school would in a few 
years be established, which would rapidly extend of itself. The Commissioners and Administrators of our African Protectorates might be requested to assist in the experiment by ascertaining whether volunteers from the native schools can be found for the purpose. Every assistance to such a scheme may be confidently anticipated from the Indian Government, who have long had practical experience of the enormous advantages of native labour in the field of surveying.

This resolution will in due course be submitted by the British Association to those Government offices, societies, and administrative centres, both at home and abroad, which are concerned in the survey of Africa. Meanwhile a few words in the R.G.S. journal, explaining in rather fuller detail the object of the proposals embodied, and the manner in which the loyal Geographical Society may be able to further those objects, may be useful.

We have, first of all, to recognize the fact that the field of geographical enterprise presented by the terra incognita of Africa is growing exceedingly narrow. There are no more sources of mighty rivers to be traced out; no more "Mountains of the Moon" to be set on a geographical basis; no more big lakes to be dubbed by royal names; and no more regions of outer darkness to illumine. We have arrived at a day of comparatively small things, a prosaic day of patient local enterprise, of regulation Government surveys, and of contracted gfographical exploits under Government direction. And just in proportion as we have a narrower area to work in, we require more solidly accurate and scientific geography to fill those areas. In short, the geographical work of the future, whether under Government supervision, or in the hands of the more or less irresponsible explorer, should possess those technical qualities of accuracy, breadth, and style which will entitle it to take its place in the finished first map of the continent. Such work may appear to be rather beyond the attainment of the average traveller; and it might even appear desirable that the Royal Geographical Society should rest content with the magnificent achievements of the past, and leave that which is still uncertain in the physiography of Africa to the surer, more accurate, more scientific, and infinitely slower processes of Government professional survey. But we have bad instances enough lately to prove that accurate and scientific geography is not at all beyond the reach of the ordinary educated traveller, provided he has proper means and assistance at his command; and we have only to examine carefully the new map of Africa, ${ }^{*}$ and measure up those areas which have yet to be mapped, to realize that its requirements are still so enormous that if we wait for the slow tide of regulation surveys to cover the unfilled spaces of the continent, we may wait a very long time indeed. Referring only to those districts of Africa which are more or less directly under the British protectorate in the Sudan, East Africa, Central Africa, South Africa, and West Africa,

* See Mr. E. G. Ravenstein's map, appended. 
we find that there cannot be much less than $2 \frac{1}{2}$ millions of square miles of territory which require accurate geographical mapping for military and administrative purposes. This, of course, implies that we do not trouble ourselves about districts under the protection of other European powers than that of England, only confining our attention to territories about which it is absolutely essential that we should possess accurate information. It is difficult to compare this mass of prospective mapping with any results achieved elsewhere under conditions sufficiently similar to justify the recommendation of definite methods in order to attain similar results. Probably the general physiography of Africa, and its conditions of life (regarded from the surveyor's point of view) more nearly approach those of Asia than they do those of Europe or America. It is true that in Asia our direct national interests do not extend anything like as far. All the peninsula of India, including the Native States and Burma, with the Himalaya on the north, hardly cover a million and a half square miles. If, however, we include the transborderland of the west, and the trans-Himalayan plateau or highland country (all of which is directly related to India, and has already fallen within reach of exploratory survey), we shall more nearly approach the weight and value of that huge geographical enterprise which lies before us in Africa, and we may find ourselves finally justified in drawing on our Asiatic experiences for certain general deductions to guide us in tackling the great African problem. It is idle to make comparisons between the physical conditions of Asiatic and African geography; equally idle to balance the idiosyncrasies of the Asiatic races against those of Africa, considering the enormous area of infinitely varied physical aspect and the wide diversities of race and nationality which distinguish both continents. Special methods to meet special conditions will be requisite in Africa just as they have been needful in Asia. It is only possible to indicate the general character of those methods of map-making which are likely to be just as applicable to the greater part of the African continent as they have proved to be in Asia. One thing at least is clear, i.e. that every factor that can be utilized to multiply the great sum of geographical map making in Africa should be utilized to the very utmost.

The first, and perhaps the chief, of these factors is to be found in those Government surveys which have already been initiated in many parts of the continent, and which are to be carried out under a recognized system of technical detail which will ensure a high standard of accuracy in the field and of final expression in the shape of maps. With this organized system-or rather with those many units of it which at present appear to be independent of each other and of any central control-the Royal Geographical Society has little to do. It involves, in the first instance, an elaborate programme for a "geodetic arc" which is to extend from "the Cape to Cairo," the triangulation No. VI.-DeCember, 1901. 
of which is to be carried out with all the rigorous attention to minute accuracy that the science of geodesy demands. This scheme of initial triangulation is to serve two purposes. It is, in the first place, to assist in the final determination of the exact figure of the Earth-a purely scientific purpose of the highest interest to mathematicians, but one which is never likely to have much practical effect in revising the world's mapping. This is strictly the "geodetic" aspect of it. But it should also serve the purpose of a great continental backbone to a general system of triangulation extending therefrom into all parts of Africa. In itself it will only cover a narrow width of country somewhere about the meridian of $30^{\circ} \mathrm{E}$. long., but it will furnish the basis throughout its length of points exactly determined from which other triangulation of a more or less rigidly accurate nature may spring. From this point of view it is a practical necessity. No country in the world that professes to illustrate its physiography with maps of scientific accuracy has ever been able to neglect it. The want of it, even in comparatively restricted areas, has only landed the governments concerned in uncertainty and confusion, which have led to delay and expense in all forms of economic development. From these other less rigid systems of triangulation which spring from the geodetic arc there will spring again yet minor systems, until the whole country is covered with a network of points; and finally the topographer will be introduced to complete the mapping. This is the ordinary process of survey evolution where accurate and satisfactory mapping on varied scales is necessary for economic purposes; and it need hardly be added that it will be just as necessary in Africa as it has been found to be elsewhere. But all this systematic and regular process of survey must be initiated and directed by Government, and it will necessarily be a slow and tedious process. Money must be raised for it, and a trained staff of officers and assistants organized to carry it out. It will take some years to train a really efficient staff of topographers alone; and if we are to judge by the average rate of progress maintained in the past, when systematic surveying of this nature has been adopted, we could not reasonably expect to possess even a first map of all our African protectorates on a scale sufficiently large for military or administrative purposes within the next half-century at soonest. But whilst all experts are prepared to maintain that the primary basis and support of a wellconstructed survey, covering such a vast area as is presented by our African protectorates, must be triangulation of a nature which can claim to be called geodetic in the strictest scientific sense of the term, they do not all of them advocate the principle of waiting for the first mapping of these important states until that geodetic basis is complete. It would be well, no doubt, if so satisfactory a bed rock for all subsequent operations could be secured, but the demand for maps of such a class as will serve the purposes of administration, of public works, or 
of military movement is far too urgent to permit of the delay that must be involved in preparing it. Accurate geographical maps are the great necessity of the present, and there is not an administrator in Africa who is not crying out for them and doing his best to get them. Thus it bappens that there is a vast amount of mapping already in progresssome of it under Government direction, and some of it colonial-which (good or bad) will form another factor in the final sum of African mapmaking. All of it is equally independent of that geodetic basis which

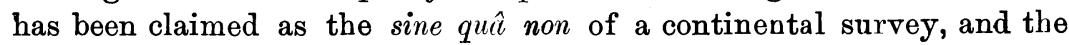
question arises whether all this material can be finally pieced together and fitted into the complete map product without confusion and difficulty when the time comes for the inevitable compilation.

This depends on what other system of triangulation, or what substitute for triangulation, has been made use of in the absence of the strictly geodetic class; it also depends, to a certain extent, on the adoption of unity of scale and of linear measurement throughout the varied areas of survey. It is to these important points that the resolution of the British Association was designed to draw the attention of those administrative authorities under whom scattered surveys in British protectorates are now being pushed forward; and there is reason to hope that administrative authorities of foreign territories adjoining those of England will also recognize the advantage of these proposals, tending to the attainment of a scientifically accurate map of Africa as a whole. But the colonial surveys, which are already far advanced, have not recognized these principles. Strange as it may seem, although South Africa (i.e. Cape Colony and Natal) has for some years been traversed by a magnificent system of geodetic triangulation of the very highest value (the only true geodetic triangulation in Africa), none of the colonial surveys have been either based on it or adjusted to it. At present it stands alone as an abstract scientific enterprise, with no practical or utilitarian outcome whatever. And the result is that when the great accumulation of colonial estate maps were patched together in order to compile a practical military map, it was found that (possessing no general basis of triangulation) there were internal discrepancies which absolutely invalidated the map for military purposes. Such a combined patchwork of local surveys is of little or no value as a general map of the country even for ordinary civil and administrative purposes. For instance, it would be unadvisable to depend on it for the allignment of a railway or a boundary. Very considerable expense and delay must be incurred before a really satisfactory map (even on a small scale) could be constructed out of such material. The Government surveys in the protectorates, in the Transvaal, and in Egypt (equally independent of a geodetic basis) are conducted on the more or less regular lines of preliminary triangulation and subsequent topography, and they should not only be effective first maps of the 
country they represent locally, but they should be readily adjustable (without appreciable error) to the final framework which is to give each local series its true geographical position as soon as that framework is ready. These surveys would be officially classed as topographical, but the map results must often approximate to that which we now define as "geographical" when no rigid rule of technical procedure can be followed. Triangulation may sometimes be an impossibility (as it usually is in West Africa), in which case elaborate topography is out of place, detail is scanty, and the process of surveying: becomes a process of exploration with a small-scale map as the result. Such work can only rank as geographical surveying, and it may be pretty safely assumed that very large areas indeed of the African continent are suited to this form of work only. But geographical survey should be by no means limited to those areas: which are unsuited to a more elaborate system. On the contrary, it would be well if geographical survey were to precede all other forms of survey everywhere. For a vast proportion of the continent of Africa (as of Asia) it will inevitably be found that nothing better will ever be needed; and even for that which is destined hereafter to develop under British rule into a full measure of civilized prosperity, the process of development will be greatly accelerated by the assistance of a good general geographical knowledge of the country beforehand. There is no necessity to enter into details of what constitutes geographical surveying. A most excellent book on surveying has recently been published in America, wherein "Exploratory" and "Geographic" surveys. are treated for the first time as distinct branches of the general art of topography.* The main points to note are, (1) that geographical surveying depends as much on sound triangulation (or its equivalent), and demands as much attention to accuracy, as any other form of survey; (2) that it can be made to fit with certainty into its right position (as coordinated in latitude and longitude) whenever that position is determined by geodetic measurement; (3) that it is exceedingly rapid in its development and comparatively cheap. All those surveys in Africa which have been carried out for boundary purposes, as well as those military surveys which, under Major Jackson, Captain Close, and Mr. Casgrain, have already spread over a great part of the Transvaal, rank as geographical surveys in so far as they have been conducted for the production of maps on a small scale for illustration of the features of the country as a whole, and not for purposes of local defence, etc. Hundreds of thousands of square miles of territory on the Indian borderland have been surveyed on geographical scales by methods which, whilst they follow

* ' Topographic Surveying, including Geographic, Exploratory, and Military Surveying.' By H. M. Wilson. John Wiley \& Sons, New York, and Chapman \& Hall, London. See also list of works bearing on the subject of geographical surveying at. the end of this article. 
the recognized system for topographical surveying which is common to all countries so far as is practicable, do not pretend to adhere to any rigid form of procedure where the recognized systems are impracticable. In days that have hardly yet passed by, opportunities which are now utilized for a geographical survey would have resulted in a thin line of traverse flanked by wide blank spaces where no feature was delineated, although much of the physiography of the country must have been within easy range of vision. The difference between these efforts on the part of early explorers and the infinitely more comprehensive illustration of the topography of a country which is now demanded, is due partly to the immense improvement in the graduation of the smaller classes of instruments, but chiefly it is undoubtedly due to the thorough knowledge which is now acquired of the capabilities of the plane-table by well-trained topographers. Instead of the thin red line of traverse, we demand square maps showing every topographical detail which is appreciable on the scale of survey; and we further demand that hundreds of square miles of mapping should be turned out where ten sufficed before; and that all of it should be so fitted within certain well-fixed points that we can determine with certainty the co-ordinate position in latitude and longitude of every feature of the map to a degree of exactness that betrays no error on the small scale of the mapping, when the mapping is tested by the rigorous methods of final geodetic, or first-class, triangulation. This is what we call geographical surveying, and it is a class of surveying which is but half appreciated in England, because in England there is no opportunity for its practice or illustration. It is, however, well understood in America, Russia, Germany, and France, and it has been invaluable to India. Geographical surveying should specially appeal to the members of the Royal Geographical Society, for it places an agency within the reach of every member of the Society which may result in most useful additions to the sum of our geographical knowledge, not only in Africa, but wherever that knowledge is weak. So far as Government surveys are concerned, the R.G.S. can hardly ofler any assistance which promises to be practically useful. It can at most but represent the opinion of an influential body of geographers in favour of any method which will ensure unity of scale and homogeneity in the final map-results. But in the broad realm of geographical exploration there is ample room -room, indeed, so ample that it seems hopeless to expect that it will be adequately filled for many years to come-for those expeditions, conducted either in commercial interests or for the simple sake of adventure, which, extending far beyond the region of settled administration and regulation survey processes, might result in the acquisition of geographical map information quite good enough to take its place in line with the permanent map records of Government. It has been so in Asia, and it may be so in Africa. If every independent 
explorer would work intelligently on certain fixed methods, there would gradually be amassed so great a store of information of permanent geographical value that we should soon be in a position to deal with topographical certainties in arranging boundary demarcations or in projecting the general economic developments of the country.

I have already said that the fundamental support of good geographical work is a thorough knowledge of the capabilities of that most useful instrument the plane-table. I may now add that, in order to obtain that thorough knowledge, years of experience, united to a special talent and unusual powers of observation, are necessary. The process of the evolution of a firstrate topographer is a process of selection in the first instance, and of careful training afterwards. It is not a course of training for a few months at a military or geographical school that will result in the acquisition of the trained hand and eye of the artist, united to that topographical instinct which teaches a man to identify the features of a varied landscape from every point of view, even when we have secured the physique, the powers of adaptation to unequal circumstances, the endurance, the patience, the tact, and the indomitable perseverance which distinguish the best topographers. Technical training must be allied to practical experience, and it would be as absurd to expect a man to be a good topographer because he knows the theoretical use of the plane-table, as that he should become a good shot because he knows the use of a gun. Yet, judging from the composition of some of the survey parties at work in Africa, this is exactly what is expected. Obviously, therefore, we cannot ask the promoter and organizer of an expedition-the man who has to bear the weight and responsibility of leadership, who has his time most fully occupied in arranging details of the daily march, and his mind full of many other important interests than those which concern the geography of his surroundings-to undertake such an allabsorbing and (at times) perplexing duty as that which is involved in the actual mapping of the scene of action. The most we can ask is that he should supply himself with all the necessary data at starting on which to base his work, and that he should know enough about surveying to carry out the preliminary triangulation, and make the necessary astronomical observations; that be should, in short, be sufficiently well trained himself to keep a trained topographer straight, checking his work, and supplying him with points to work upon-and this indeed is a good deal to ask. It is by the association of a trained professional topographer with exploratory expeditions in Tibet, in China, on the Burmese frontier, and in Persia that we have acquired the best part of our map knowledge of those countries. It is a knowledge which will doubtless in time be superseded by more regular and systematic surveys than those which have hitherto been possible over those areas which promise to repay closer examination, but over other 
and far larger spaces it is probable all that will be practically wanted for many decades to come. It is, at any rate, sufficient to indicate in what directions such closer examination is desirable, and consequently it is of infinite practical value. But for Africa, where are we to get the trained topographers who must eventually furnish the grit and backbone of African mapping as they have furnished it in India and beyond the borders of India? There is no topographical staff in England as there is in Russia or America or India, and there is no opportunity within the restricted area of Great Britain for the training of such a staff. How are we to get the men we want? It is true that very great advance has been made in late years towards the training of officers. There is a most excellent school at the Royal Engineers' headquarters at Chatham (organized and superintended by Major MacDonnell), which has at any rate led to a far wider and more comprehensive grasp of the whole subject of military map-making by our military authorities than ever existed before; and there is a training class connected with the Royal Geographical Society which has been working towards the same end for years. But it cannot be too often repeated that the limited and restricted practical instruction which is all that is possible in England can never turn out topographers such as may be found in numbers in the field of geological survey in Canada or the United States, or on the borders of Russia (wherever she extends those borders), or on the wide extended frontiers of India from Persia to Burma. Neither can Africa draw on India to any great extent for assistance. The requirements of India are sufficient to occupy her whole staff, even if financially it were possible to burden India with the cost of training men for foreign service. It is, moreover, doubtful how far the native of India would be successful in dealing with the native of Africa. Much of the success of the Indian system is due to the practice of training natives of all nationalities for the special object of working within the limits of their own countries. So far as Indian natives have been employed in Africa, the experiment has been distinctly successful, and the record of their work on the part of administrators has been invariably favourable. But they have not been utilized much for purposes of exploration, and it is on this capacity that their assistance now is so urgently needed. The most that can be expected from India is the advantage of the Indian training school for purposes of instruction. In this direction (and in one other which will be noted presently) it is possible that India may extend a helping hand to Africa to some practical purpose.

There are two distinct classes of topographers needed in Africa, viz. European and native, and it must, I think, be recognized as a necessity that the practical training-ground for both should be Africa itself. Already the Transvaal and the Orange River colony have afforded our military surveyors the opportunity for, at least, a partial training in 
topography of a section of Royal Engineers drafted out to South Africa for that purpose. The work that has been done for military purposes is, for the most part, of that nature which we now class as geographical, and it will furnish a very fair sample of what may be expected from such an agency in future. If successful, it is much to be hoped that here is the foundation of a trained corps of military topographers who will hereafter be fully as usefully employed in times of peace as in times of war. The process of training has, at any rate, been in most capable hands. The experiment must result in really trustworthy indications. There are, again, a number of men already employed in African fields who have been trained in various schools (some of them hold the R.G.S. diploma), none of whom could possibly rank originally as trained topographers, but amongst whom there must be some who have gradually, by force of circumstances, acquired a considerable practical knowledge of the art. And there is yet again another source of supply which is not as fully known as it should be. The Government of India has decided that after the age of fifty-five no man is to be officially considered capable of undertaking further civil work which is not of an administrative character; so that year by year a certain number of men are dismissed from the Indian Survey Department, on pensions, who are not only capable, but most willing, to take the field for another five or ten years. Amongst them are some of the most experienced surveyors and best instructors that India has produced, and none could be more technically efficient than they to undertake the superintendence of African surveys and the training of topographers, provided that they can (at their age) fit themselves to the new field and the requirements of African administration. Here the Royal Geographical Society may usefully extend a helping hand. It is proposed to keep a register of the names of all such men at the Society's office (along with a general record of the names of all men whom the Society can confidently recommend in connection with their own school), and to circulate that register from time to time amongst those offices which have to do with the organization of surveys in Africa or elsewhere in the colonies. That is to say, that the Society may undertake to introduce the "supply" to the "demand," but will of course go no further than the introduction.

On the whole the prospect of gradually raising an efficient staff of European workmen in the field of topography appears to be by no means a hopeless one. But for one European who takes the field in India, there are at least four or five natives. Economy, no less than efficiency, makes it a sine quâ non that most of the exploring work in trans-border countries should be carried out by natives of the country; in fact, India could never do without them. No solid reason has ever yet been adduced against a similar employment of trained natives in Africa. It will certainly take some years before any experiment in this direction can be satisfactorily concluded, because it will take time in 
the first instance to select likely pupils (although the sources from which they may be drawn are as infinitely varied in Africa as they are in Asia), and still more time to train them; but the broad assertion that there are no natives of Africa who will exhibit the same peculiar aptitude for geographical map-making which is so marked a feature in natives of all castes and nationalities in India, is hardly to be accepted until the experiment is tried.* But it must be remembered that the experiment, to be satisfactory, must be on a considerable scale and thoroughly conplete. It is not every native of India who possesses the idiosyncracies of an explorer, and a special aptitude for topography. On the contrary, the process of selection is one demanding infinite resources of time and patience. One great success is assuredly balanced by at least twenty failures; but then, the one success is well worth all the time and patience bestowed on those twenty failures. We can but hope that the settlement of South Africa will lead to a full and careful consideration of the best means to procure that great desideratum - a thoroughly accurate and homogeneous geographical map of all our African possessions; and that the training of a staff of native topographers will be admitted as one of the means to the end in view. Whether they are trained in a central topographical school analogous to that at Dehra in India, which is, I understand, already contemplated; or whether the experiment is made by the formation of a topographical party for the special object of geographical exploration, seems to be a matter of detail of no great importance. Both methods have been found to work efficiently. What is wanted eventually (say in four or five years' time) is a capable and extensive staff of topographers for Africa, both European and native, on which explorers, whether they are Government officials or bound on private enterprise, may indent (as they indent in India) for that assistance in the technical details of map-making which it is quite impossible that any but a fully trained topographer can give. With that assistance every geographical society in Great Britain could lend a useful hand towards the evolution of the map of Africa.

\section{List of Publications bearing on Geographical Surveying.}

' Handbook of Professional Instructions for the Topographical Branch Survey of India Department.' Prepared by Lieut.-Col. St. G. C. Gore, R.E. Published in Calcutta.

'Aid to Survey Practice.' By L. D'A. Jackson, A.M.I.c.e. London, 1889.

R.G.S. 'Hints to Travellers.' Woodthorpe's article on plane-tabling.

Professional Papers Royal Engineers (Occasional Paper Series), vol. xiii. paper v. by Holdich; vol. xiv. paper ii. by Talbot; vol. xxvi. paper i. by MacDonnell. R.E. Institute, Chatham.

* To a certain extent it has already been tried. A large area of most useful geo. graphical mapping in West Africa has been contributed to geography by a native of Africa-Mr. Fergusson. 


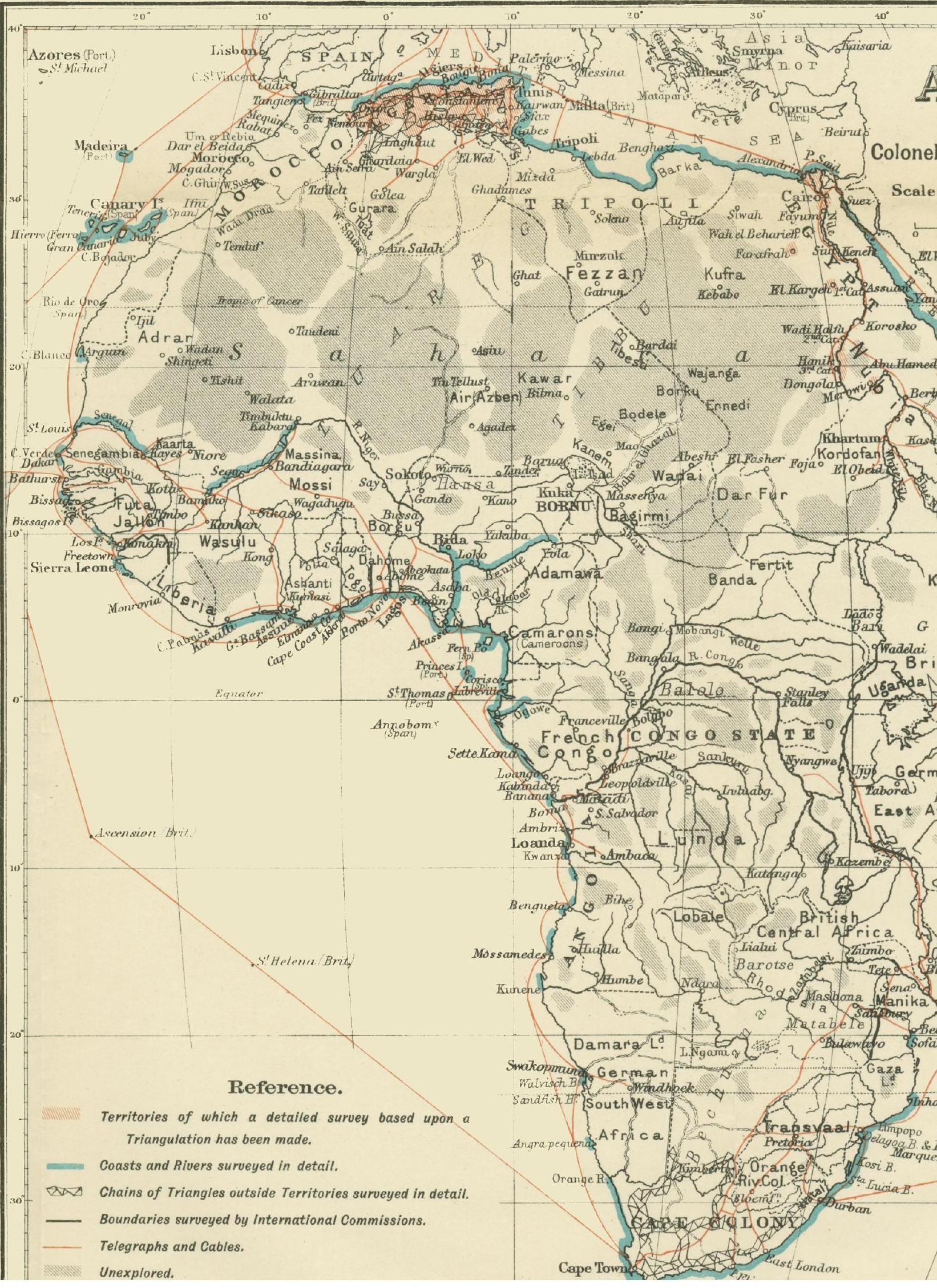




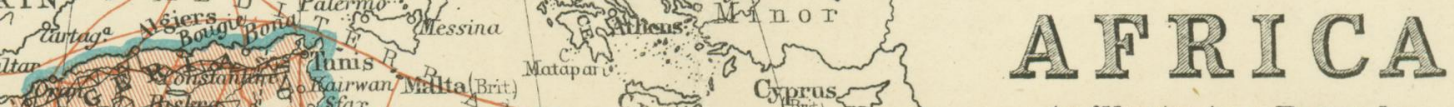

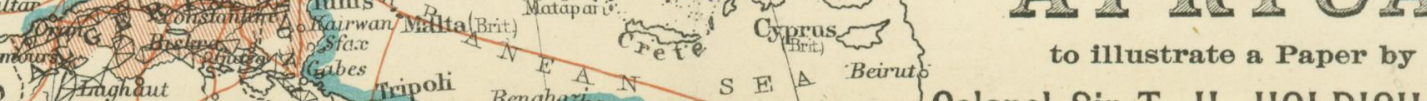

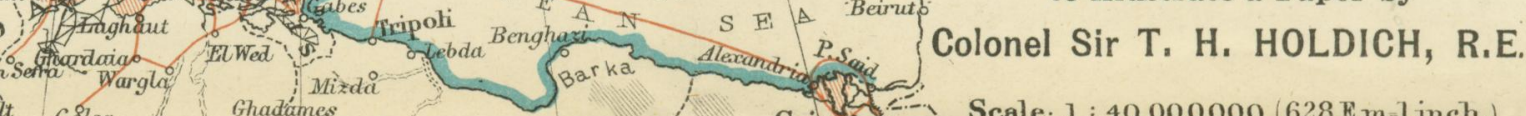

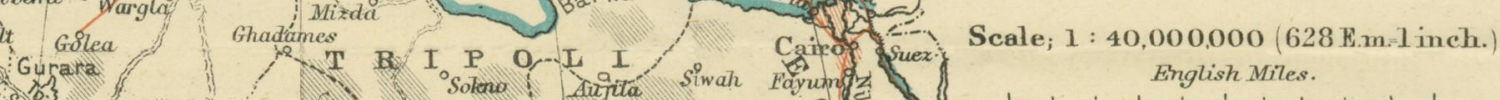
is

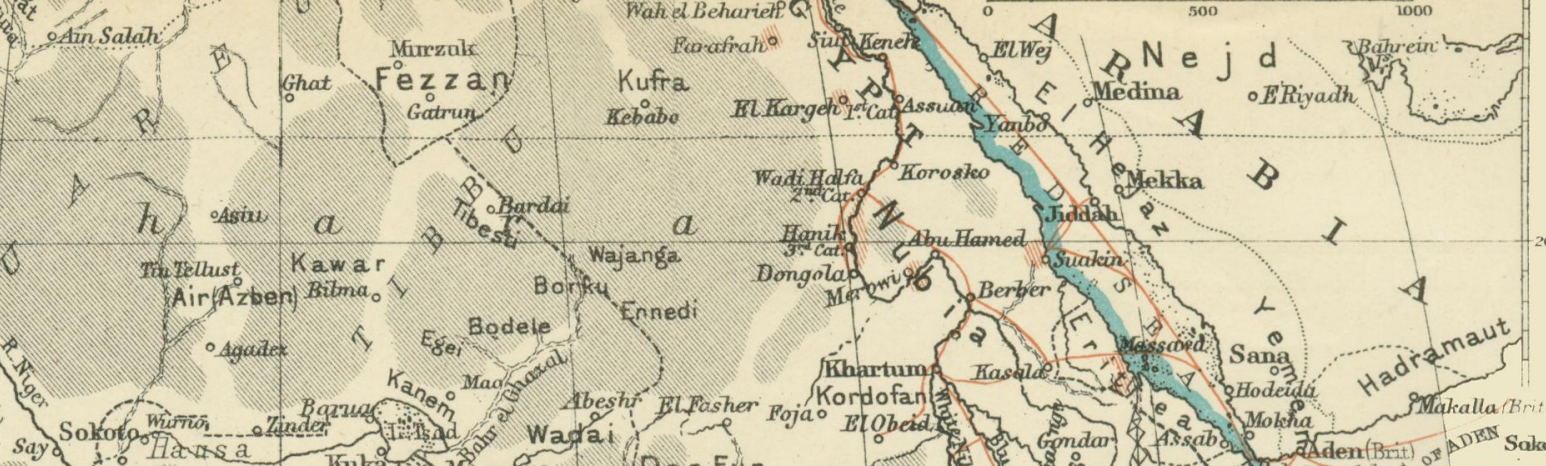

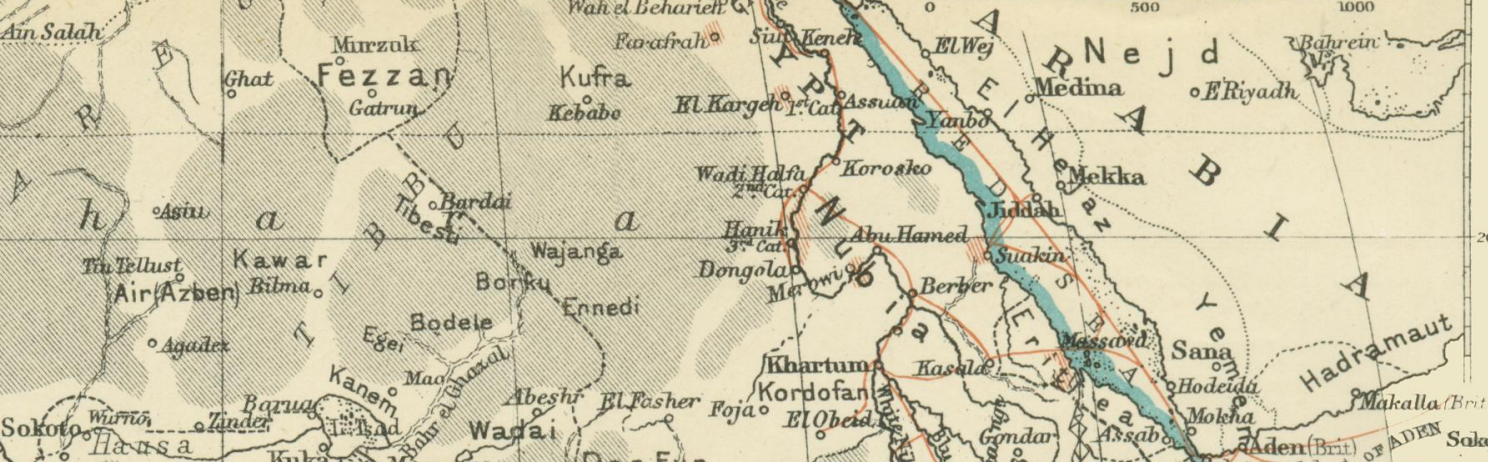

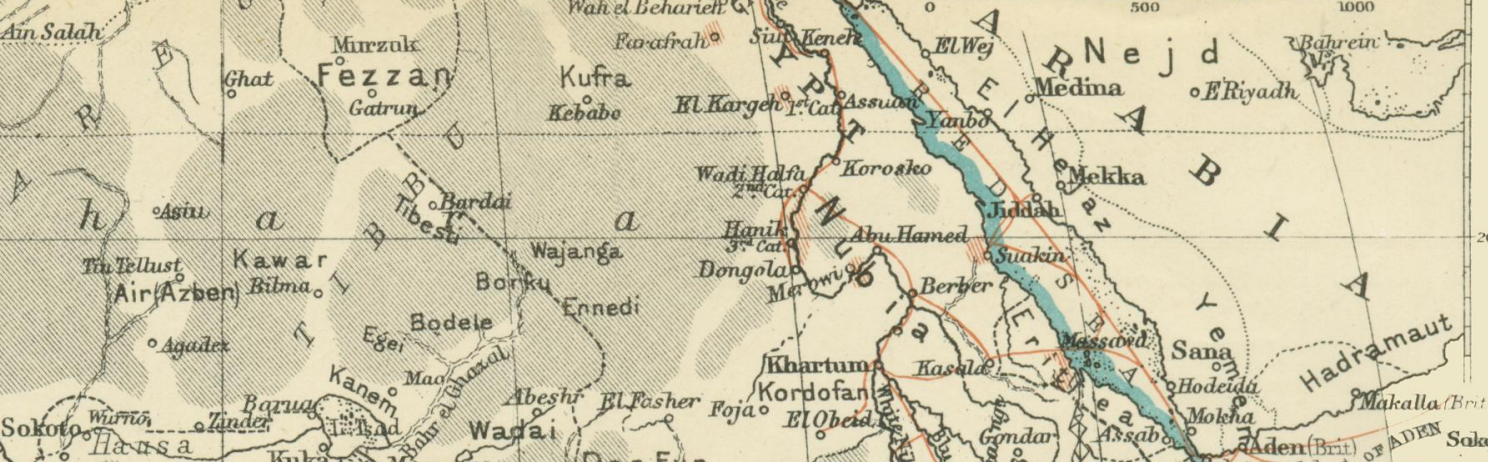

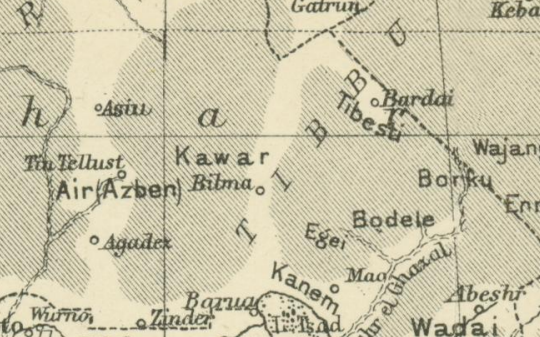

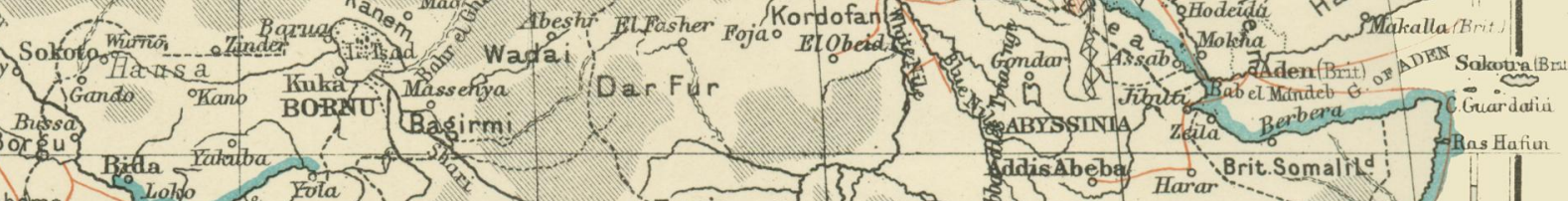

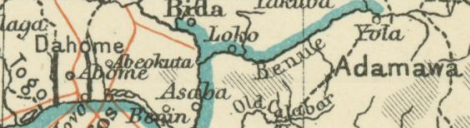

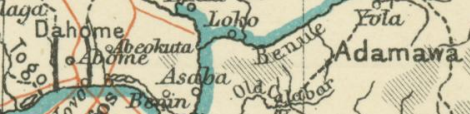
Be

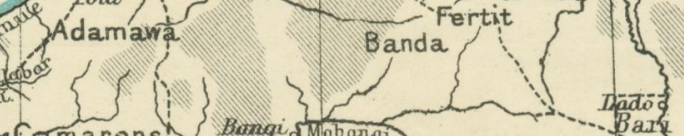

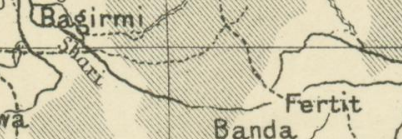

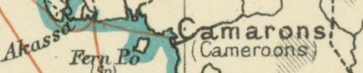

Princes Iot

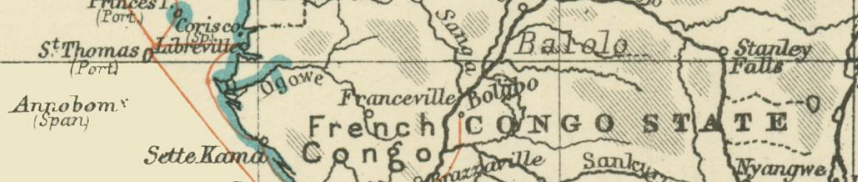

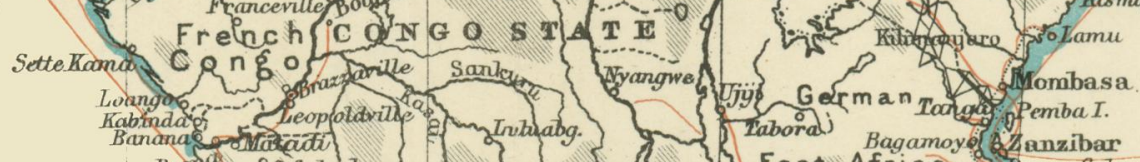

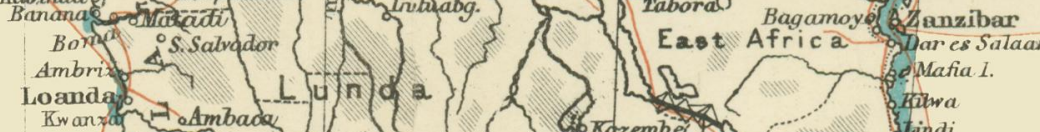

Loandar

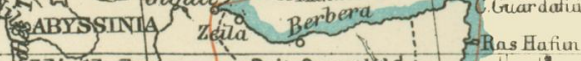

iruey based upon a

surveyed in detail. Commissions.
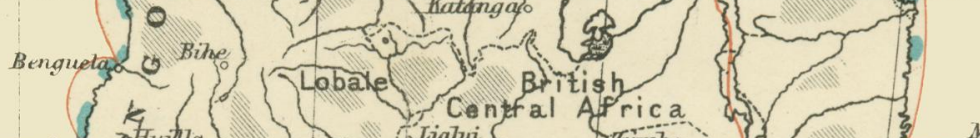

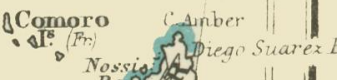

Mossamedes of

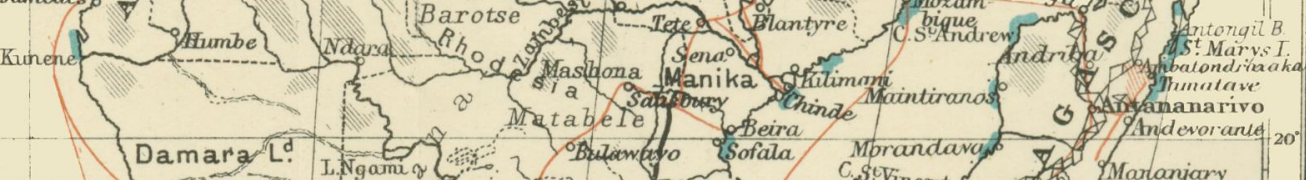

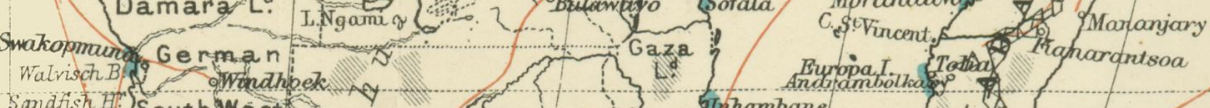
Sardish HP: South We st th

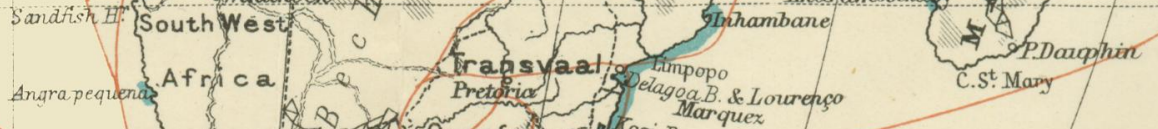

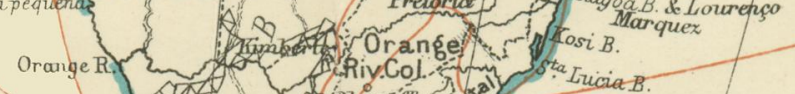

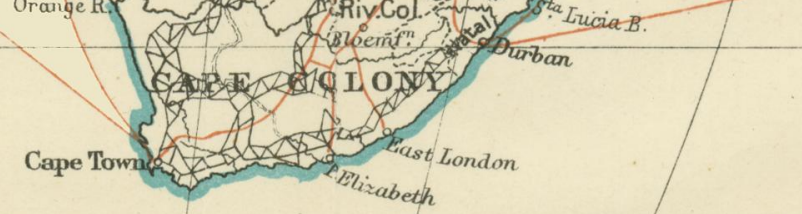

